\title{
Amir Zelinger
}

\section{Unnatural Pet-Keeping: Pet-Custody Disputes in the Aftermath of Hurricane Katrina}

Introduction: Katrina, Pets, and Society. About two weeks after Hurricane Katrina made landfall on the Gulf Coast, New York Times journalist John Leland asked dog owners who were walking their animals in Central Park about their emotions in light of the numerous pictures of stranded pets coming from New Orleans. In most cases, the rescuers did not allow pets to be evacuated together with their owners, and these animals were thus left behind and forced to confront the devastation wrought by the inundation of their habitats alone. Leland wrote about the reaction of one New York pet-keeper: "For Elizabeth Finch, the owner of two dogs named Zorra and Hans Blix, the sight of citizens forced to choose between their pets and their safety was, like the disaster itself, indicative of broader social rifts. 'Not to equate people with animals,' she said, 'but this fits into a bigger model of discrimination'” (Leland).

When Leland and Finch use terms such as "social rifts" and "model[s] of discrimination" in reference to pets, their allusions fit quite well with some of the main narratives typical of Katrina. The hurricane, which assailed the Gulf Coast at the end of August 2005, resulted in more than 1200 casualties and over $\$ 108$ billion in damage. It was the third deadliest, and by far the costliest, tropical cyclone in the history of the United States (Blake, Landsea and Bigney). However, Katrina represents much more than just destruction caused by exceptional natural events. In the media coverage during the weeks after the hurricane itself, and in academic publications in the years that followed, Katrina has been largely perceived as what might instead be termed an "unnatural disaster." This framing pertains to the evident social dimension of the catastrophe, which in this case became much more blatant and palpable than in other natural disasters in history. The social questions surrounding Katrina are fundamental ones, involving race, class, hierarchies, and segregations, all of which in turn position the social weight of the event at the center of even the most basic discussion of it (Dynes and Rodriguez).

Katrina was an "unnatural disaster" because it was first and foremost about the social. Probably more than any other catastrophe in recent history, Katrina revealed that "disasters and their impacts are socially produced, and [that] [...] the forces driving the production of disaster are embedded in the social order itself. [...] The origins of disaster 
lie not in nature [...] but rather in the ordinary everyday workings of society itself" (Tierney 4-5). For example, Mississippi and Louisiana, the states that were most severely hit by the storm, are also among the poorest in the USA. In New Orleans County, which suffered the most in terms of death rates, more than twenty-five percent of the population lived below the poverty line at the time of the disaster, making it the most socially vulnerable county nationwide. This social precariousness intersected with the natural threat, insofar as this poor population was extremely ill-equipped to cope with the catastrophe (Hartman and Squires; Haney, Elliott, and Fussel 87-93; Reilly 247). Prior to Katrina, moreover, New Orleans was a city sharply segregated along racial or ethnic lines: $67 \%$ of its population was African American, mostly concentrated in inner-city poverty-stricken neighborhoods like the Lower Ninth Ward. This location also happened to be among those that were most strongly devastated by floods after the levees, which were intended to defend residential areas, collapsed. ${ }^{1}$ All in all, one can conclude that the social conditions underlying the catastrophe of Katrina existed well beforehand, in the long past preceding the event itself (cf. Bankoff, "Time is of the Essence;" Tierney 40). As such, when the hurricane eventually reached the Gulf Coast, it merely catalyzed the deep-rooted conditions of marginalization of specific groups and of uneven distribution in the ongoing history of New Orleans, albeit this time through the impact of a "natural" disaster (Waterhouse 169-170).

Interestingly, when Leland and Finch speak about the side of Katrina that pets experienced, they do so without hesitating to refer to a general suffering tied to some "hard" social elements like discrimination and marginalization similar to the ones mentioned above and embedded in the story of Katrina at large. Apparently, the hurricane, with its profound and gloomy social dimension, also exemplified the inextricability of pets both from human society and from pivotal social issues. As press reports and scientific research during the disaster and in its aftermath have demonstrated, concern for their own pets was one of the most decisive factors that influenced people's decision not to evacuate before the storm (Hunt, Al-Awadi and Johnson; Zotarelli; Grimm 84). Many owners, especially those without cars, faced difficulties in taking the animals along and chose to stay behind when confronted by the threat of being separated from their beloved dogs or cats (Smith, Hurricane Katrina 24, 30). The close attachment keepers felt to their pets also complicated rescue efforts, as people once again refused to leave their pets behind. This often resulted in rescue squads resorting to violence - pushing pets out of rescue boats (Grimm 82), or even threatening evacuees with guns to force them to leave their animals behind, in accordance with federal policy disallowing animals of any kind to join evacuation transports. Consequently, Katrina provided insights into the central position of pets in the social fabric of America and their influence on people's actions. As noted by author 
Douglas Brinkley in his popular recounting of the events, thanks to Katrina "the nation was beginning to understand that animals are part of U.S. society and can't be separated from their human companions in good times gone bad" (518). ${ }^{2}$

Analyzing disputes over the custody of many of these displaced pets in the aftermath of the catastrophe, I argue in this article that Katrina not only laid bare this general partnership of pets in society, but also allowed us to obtain a rare insight into the embedded nature of pet-keeping in some of the "deeper" social processes that are so inseparably associated with this thoroughly "unnatural disaster." In the same way that Katrina brutally brought to the surface many of the social grievances that American society had been disinclined to confront openly in the decades prior to the disaster, especially entrenched racial discrimination (Ishiwata), it also bluntly revealed the extent to which present-day human-pet relations are interwoven with similarly controversial social concerns.

When considering such an ostensibly "innocent" leisure activity as caring for companion animals such as cats, dogs, parakeets, or rabbits, one does not usually think of issues like hierarchies, distinctions, or inequality. Furthermore, the personal relations between a pet-keeper and their companion tend to become almost exclusive associations, excluding elements of the wider context within which those relations are being played out. The kinds of interactions between humans and pets that have been most readily highlighted in Human-Animal Studies are personal ones, those pertaining to the contact between the keeper and their individual companion "as the smallest unit of being and of analysis" (Haraway 165). In the last couple of years, however, an increasing number of works have turned their attention to the ways in which petkeeping is anchored and made meaningful in view of the complexities of modern, capitalist societies, with their concomitant inequalities, segregations, and discriminations. These works explore the ties that enmesh pets in matters of race, class, and gender, and that make pet-keeping anything but an "innocent," purely personal undertaking (Nast; Glick; Weaver; Kim 272-279). They show how human conflicts over these matters sometimes have an impact on the relationships that develop between humans and companion animals. They point out, for instance, that hegemonic perceptions of "good" vs. "bad" human-pet relations are rooted in more general hierarchizations among different social and racial groups, and in turn serve to amplify these hierarchizations. By way of juxtaposing human-animal relations with main issues highlighted by recent studies in the sociology and historiography of natural catastrophes (cf., Bankoff, "Learning about Disasters from Animals"), this article aims to contribute to this effort of disclosing some of the critical social "burden" that caring for

Humanimalia: a journal of human/animal interface studies

Volume 9, Number 2 (Spring 2018) 
animal pets necessarily carries. Taking Katrina as an example, it shows that just like disasters pet-keeping is closely linked to society's deepest concerns.

Especially in Western societies, the social "burden" that pet-keeping carries is already revealed in the way the term "pet" is being defined. In the United States and Western Europe, dominant understandings of "pets" refer to them as animals that are privileged in comparison to all other domesticated animals - thanks to the special treatment they receive from humans. From a middle-class perspective, pets are the animals that

We stroke $[\ldots]$, cuddle $[\ldots]$, play with $[\ldots]$, groom $[\ldots]$, and ensure that they receive all the exercise and social contact they need to keep them happy and healthy. They are regularly supplied with specially prepared, vitamin-enriched food, provided with warm and comfortable places to sleep, and at first signs of illness, are immediately taken to expensive and highly trained doctors. (Serpell, In the Company of Animals 14)

The perception of "pets" as privileged animals compared with livestock implies that pet-keeping itself is a privileged undertaking. According to this perception, a "pet" is not every dog, cat, or budgerigar that is kept at the home or its surroundings, but only the ones that are being taken care of in a way that ensures their greatest possible wellbeing. Owners that do not, or are not able to, take "good" care of their animals are not genuine pet-keepers. They fail to give them the things that would make their lives pleasurable, and thus to elevate them to the status of "pets." If we accept the privilegebased perception of pets we must concede that pet-keeping is the exclusive domain of a relatively small segment of society. If the number of pet-keepers is small, it would not be misleading to assert that "the majority of pet-owners spare no expense to ensure that their animals are as happy, contented and secure as they possibly can be" (15).

This perception of pet keeping as the exclusive domain of the rich has huge significance for the custody disputes discussed in this article. These disputes revolved in the majority of cases around animals that, so to speak, climbed the social ladder in the wake of Katrina. Before the storm, they belonged to poor families from disadvantaged communities in Louisiana and Mississippi. After the storm, they found themselves in the homes of much more affluent people in Florida, California, or New England, who were able "to spare no expenses" to ensure their happiness and treat them as genuine "pets."

This development was the result of the separation that Katrina brought about between the pets and their owners who were not able, or not allowed, to take them along when 
they fled from the devastated areas. After the storm subsided, many of the animals that survived in their shattered homes or in the streets were picked up by animal rescue volunteer groups that reached Louisiana and Mississippi to help them. Although it is difficult to assess the number of pets impacted by Katrina accurately, estimates of about 50,000 stranded pets, with approximately 15,000 of them being rescued have been recorded (McNabb 75). Due to the limited capacities of local shelters, and the fact that many of them were flooded, many of the rescued animals were sent away to other shelters, scattered across the country. When the local situation calmed down and evacuees started to recover from their ordeals, many of them began searching for the pets they had left behind with the hope of reuniting with them. Dedicated websites, where owners could publish lost ads, were deployed for this purpose. While this led to the reunion of about one fifth of the rescued pets with their former owners, in many cases the shelters had already found new adopters for the animals by the time their original keepers were able to claim them. These new adopters were, for the most part, wealthy citizens who were willing to open their homes to the stranded animals and to help them to rehabilitate their lives. When the original owners found out their dog or cat was already given away, some of them sued the new keepers and the shelters that facilitated the adoptions for the return of their animals. It is on the basis of these disputes, emanating from an exceptional event such as a natural disaster, that I aim to unlock a possible but very poignant social dimension of modern pet-keeping, albeit one that is usually blurred and that fails to gain recognition.

The sources I used for this article are mainly written press reports about the custody disputes. As we will see, national and local media took a lively interest in the pet disputes. When writing about them, reporters usually emphasized the socio-economic disparity between original and new owners, thereby helping to situate the disputes in the larger context of Katrina's controversies. The narrative they developed is therefore a prime example of the way Katrina brought to the open the embeddedness of petkeeping in social conflicts that go far beyond the love individuals feel towards their animals. The news articles discussed document plentiful statements by the new adopters of the stranded pets. They also contain comments made by the animal welfare organizations that had rescued the animals left behind, and that later adopted them out to new foster homes. Both new adopters and representatives of animal welfare groups tended to express their opinion to newspaper reporters very openly, justifying their unwillingness to surrender pets to their former keepers and lawful owners by maintaining that the animals were better off in their new, more affluent households, where they received better care from more responsible guardians than their previous ones. Similar statements were found on websites of the organizations themselves, as

Humanimalia: a journal of human/animal interface studies

Volume 9, Number 2 (Spring 2018) 
well as on different animal welfare blogs and pet adoption portals. I also consulted publications by rescuers and other animal activists about their experiences during, and in the aftermath of, Katrina, where dominant attitudes concerning the appropriateness of certain people as pet-keepers, in contrast to others who were perceived as less qualified, are likewise documented. Analyzed together, these sources reveal a constellation in which pet-keeping is intimately related to the production of social hierarchies and forms of inequality - a constellation that only such an extreme naturalsocial catastrophe as Katrina was able to unveil.

The Long Way Home: Recovery and Pet-Keeping. The social relevance of Katrina did not end with the events of the hurricane itself, but extended well beyond them, becoming at times even more conspicuous during the phase of recovery. One of the most delicate issues in post-Katrina New Orleans is the question of the kind of city it is desirable to rebuild. As had already become clear in the first weeks after the catastrophe, the redevelopment of the city was not simply about returning to predisaster conditions. Much more significantly, it represented a fractured rebuilding that exhibited conflicting interests, ideas, and political agendas for the "new New Orleans," contingent once again mainly on race and class matters, and translated into a variety of practices of inclusion and exclusion (Gotham and Greenberg 94-133).

A case in point is that of demographic recovery: studies assert that wealthier and white residents have returned to the city and reestablished their lives there at a much faster pace and in far greater numbers than poorer and black people (Haney, Elliott, and Fussel 99-100; Steinberg 21). According to one survey of evacuees from different socioeconomic backgrounds, white populations were twice as likely to be living in their original homes during the immediate aftermath of the storm, whereas black populations disproportionately confronted long-term displacement. Many of them have been unable to recover, among other reasons due to severe financial problems as a consequence of the catastrophe (Bevc, Nicholls, and Picou 141, 146). As a result, New Orleans has experienced a kind of gentrification, made possible and brought about by the natural disaster. Owing to Katrina, the segregation along race and class lines manifest in the city's history is now deepening and intensifying (Graham 28-29). Moreover, this unequal recovery is not simply a process of "natural selection" through which people with more resources are able to reestablish themselves more easily than those who lack those capabilities and therefore lag behind. Instead, it is substantially related to an intentional policy advanced by urban elites seeking to change the local social fabric according to their own view of a "good city" (i.e. one that is prosperous, distinguished, and genteel). As an article published in the Wall Street Journal put it less than two weeks after the storm, 
Despite the disaster that has overwhelmed New Orleans, the city's moneyed, mostly white elite is hanging on and maneuvering to play a role in the recovery when the floodwaters of Katrina are gone.... The power elite of New Orleans [...] insist the remade city won't simply restore the old order.... [T] he new city must be something very different $[\ldots]$ with better services and fewer poor people. (Qtd. in Hartmann and Squire 286)

This desired "amelioration" of the urban landscape, made possible by the "shock effect" of the hurricane and the dismantling of preexisting conditions, found a practical outlet in plans that largely concentrated on the white and wealthier neighborhoods, giving preference to affluent home-owners over renters in terms of public assistance and financial aid from authorities (e.g. public housing in New Orleans has been almost completely annulled after the storm [Graham 25-29; Steinberg 18, 22; Cutter et al. 15-18, 20]). Such perceptions and practices raise questions not only about who has really come back and reestablished their former life, but also about which individuals, communities, and residential areas have the right to reestablishment, according to a certain hegemonic value system. Here we are forced to direct our view past "objective" social circumstances and onto social groups that are consciously aiming to establish themselves as better and more distinguished than competing ones, and therefore as more deserving and entitled to larger assets as part of a "healthy" recovery process that according to its intrinsic logic must be advanced unevenly.

We can pose the same questions when dealing with the issue of reestablishment of petkeeping bonds in the aftermath of the storm. In fact, pet-keeping is tightly linked to the more general question of post-disaster recovery, because in Western middle-class societies pets are perceived as creatures that are significantly bound to homes and private households. In the hegemonic perception of pet-keeping, pets are almost analogous to domesticity. They are perceived as part of the home as a site of comfort and stability in an otherwise turbulent world. Pets are believed to contribute to a feeling of "ontological security," inseparable from conceptualizations of the private domestic sphere (Fudge 13-38; Grier 58-122). The intersection between the housing problems in post-Katrina New Orleans and the reestablishment of pet-keeping relationships is clear.

As Sheila Crowley observes, Katrina created a housing crisis of historic proportions. Whereas 302,405 housing units were seriously damaged or destroyed overall, in the areas most affected by the hurricane the devastation struck $73 \%$ of the buildings. Former residents were stranded in every state in USA and even beyond its borders, and

Humanimalia: a journal of human/animal interface studies

Volume 9, Number 2 (Spring 2018) 
about 700,000 people lost their homes. Among those New Orleans residents who lost their dwellings, $73 \%$ were black and $71 \%$ came from low-income households. Once again, it was largely the poor and African Americans who found it especially difficult to restore their homes or, alternatively, to find new housing units, as authorities did not effectively accommodate their exceptional situation in this respect, either. As a result, many of them lived in trailers supplied by the Federal Emergency Management Agency (FEMA) or even in tents for long periods (months, and even years in trailers). A significant number of Katrina victims have never returned to their former homes, and some of them remained separated from family members for as long as three years after the storm. As Crowley summarizes, "Katrina is about wrenching hundreds of thousands of people from homes to which most will never return. Katrina is about the sudden and complete loss of all that home means - safety, respite, privacy, comfort, and security" (155).

With pets and owners separated and scattered all over the United States, it is clear why pet-keeping relationships were dismantled and why reestablishment was complicated, simply as one more fundamental demographic consequence of Katrina. This is a radical change in the status of pets, who virtually lost their essential role within society as creatures of domesticity and were exposed to wholly new circumstances. Naturally, this transformation was also visible along race and class lines, as some people had greater chances than others of recovery. Less privileged and more vulnerable populations were not only less likely to evacuate by themselves, and therefore more prone to being forced to leave their pets behind by rescuers (Baum 109; cf., Thompson et al.), but also had fewer possibilities of gaining access to stable housing to share with recovered pets. Many poor, black women moved again and again between different homes of relatives and friends; they were thereby forced into an extreme residential mobility that rendered the possibility of (re)establishing independent households - such a crucial condition of pet-keeping - unattainable (Pardee 68-69). In her book Pawprints of Katrina: Pets Saved and Lessons Learned, Cathy Scott summarized her experiences as a volunteer in an animal welfare group rescuing pets from the streets of New Orleans during and after Katrina. She recorded some instances of pets that were located and identified but not reunited with their owners, as well as reunions taking place a very long time after contact was established. One significant story is about Gary Karcher and his dog Himie that was rescued and brought to a shelter in Tylertown, Mississippi: "After Gary returned to Louisiana, he and his mother lived in a FEMA trailer on commercial property, where they were not allowed to have dogs. Himie continued living in Camp Tylertown until Gary could repair his damaged house;" only after nine months of separation was Gary able to move back to his restored home, and only then did Himie come to live with him again (71-72). 
Hardships of that kind even led some former guardians to relinquish their ownership of a rescued pet, preferring for it to stay with its new owners in the hope that it would be better off. Such was the case of Belinda Sumrall of St. Bernard Parish, who, upon locating her two German Shepherd females, filed a lawsuit against the Society for the Prevention of Cruelty to Animals in Montgomery County, Maryland, which had adopted them out to a local family. Once the juridical process was under way, she decided to withdraw the case: "She moved back to Louisiana and, according to her lawyer Kathryn Bloomfield, her living situation became unpredictable. Bloomfield says that '[u]pon confirmation that her two dogs were healthy and happy and staying with the family who had adopted them [...] she gave up the custody fight' " (McNabb 98-99; cf., Scott 109, 197, 200-201; Londoño). As such a story implies, one possible effect of Katrina on pet-keeping in the aftermath is the movement of pets away from poor owners and into the hands of people who could apparently make them "healthier" and "happier." Based on our information regarding the socio-economic situation of the majority of the displaced people and pet-owners, such a movement potentially has distinct social significance. It means that as far as pets and keepers are concerned, the aftermath of Katrina worked against what we may refer to as social reproduction (Katz), namely against a reconstitution of pre-disaster social contacts between people and their animals. Instead, it saw the production of new companionships, made possible by the storm's severing of old bonds.

"Bad" Pet-Keepers. The organization that Scott volunteered for, Best Friends Network, passionately aimed at reuniting the stranded pets it found with their original owners. In order to reveal matches with animals residing in the shelter, not only did they conduct a thorough investigation of lost Katrina pets websites and published ads, but they also developed a meticulous system that identified every individual animal that came into the organization's hands, and closely tracked its whereabouts:

It's a system that, when implemented, is foolproof. Each animal arriving at the center is assigned an ID number, which is etched on an aluminum tag and attached to the collar. Admission photos are taken and uploaded to a database and to the Petfinder Web site. [...] Included in the paperwork were existing and new microchip numbers, because all dogs and cats at Camp Tylertown were injected with a microchip. [...] The chips, injected between the shoulder blades, contain individual identification numbers that are readable with an electronic scanner. [...] Microchipping [...] is a major key to getting pets home (44-45).

Humanimalia: a journal of human/animal interface studies

Volume 9, Number 2 (Spring 2018) 
The fact that Best Friends resorted to this operation should be read not only as an assertion of the individuality attributed to distinct pet animals in the context of disaster resilience, but also as a firm perception that pet-keeping in its modern version completely identifies a personal owner or family and the pet that belongs only to them as exclusive manifestations (Kean; Steinbrecher 197). The topic of successful reunions and the restoration of original pet-owner relationships is a leitmotif throughout Scott's book. According to her account, the ideal of reunion informed the motivations of volunteers and was to a large extent the "driving force. It lifted morale" (164). In the apogee of one of her stories about owner and pet coming back together she maintains: "To see them together again was what the animal rescue was all about" (163). Every time a pet went home, it was announced in the camp with a ritual, during which rescuers banged together pots and pans and shouted "Reunion! Reunion!": "Reunions were the events volunteers and staffers looked forward to most" (163-164; cf., Smith, Hurricane Katrina 133-134). Imbued with this ideal of reunions, it does not come as surprise that for Scott finding a new home for displaced pets was only "the next-best thing" (209-210). Feeling less enthusiastic about adopting out to people outside of the devastated area, her heart lay above all with the locals: "Despite limited resources, despite being separated from their families and pets for months, and despite facing obstacle upon obstacle, the people of New Orleans who returned to their homes were determined to rebuild their city" (218).

Taking such attitudes about the advantageousness of reunions into account, it may seem bewildering at first glance, that, as noted above, many pets were briskly adopted out to new homes by the shelters that harbored them, and that such vehement custody disputes arose between owners and foster families that refused to hand the animals back. The reason for these refusals may lie in a different kind of social perception. Contrary to the reunion ideal, one may detect through the custody disputes that certain animal welfare groups and new guardians in fact valued the instrument of adopting out, even in cases where original owners were located. In a Petfinder forum from March 2006 concerning a rescued cat (Precious) whose owners inquired about her after she was presumably given to a new family, one volunteer commented about the events:

In my heart of hearts I feel that Southern animal [sic] Foundation [...] adopted her out. [...] The reason WHY I feel strongly that this happened, is becuse [sic] I later found out that the owners had NEVER requested a rescue of this cat, (naivity [sic], ignorance, etc.) and when it was finally rescued on Oct 20th, it probably was marked as "owner abandoned." Ann Bell, who is the director of SAF [Southern Animal Foundation], is known 
for her views on animals that were "left behind," and she feels that owners that deserted their animals, are not owners that deserve to have the animals back. [...] You know, a part of me would agree with her action of adopting Precious out, under the circumstances. It sure as heck must have been an immensely heart-rending thing, to see this cat come in, starving and dehydrated, after being trapped inside an apt for almost 2 months, with no owner requested rescue infomation [sic] tagged on her. [...] I have seen the hopeful elation of the young 16 year old owner, when I told her that I thought we were nearing in to finding Precious (after her teacher posted a Lost ad on P[et]F[inder]). I then watched her slip into dispair [sic] as the days wore on, and Precious had simply "disappeared" at Southern Animal Foundation, with no record of her. The young girl and her mother, when questioned about WHY they had not requested a rescue, said that they "did not know who or how." [...] With the above information in mind, you can see why I am "torn" in my opinion, and "understand" IF this cat was adopted out. I really stopped looking for her about a month ago, when I saw that all roads came to a dead-in on this cat. Someone knows where she is, but they will never talk. [...] On a sidenote, this 1 year old cat was not spayed.

The above paragraph may reveal some of the outlooks held by animal welfare representatives in the aftermath of Katrina. First, there is the conception that some pet guardians are not legitimate, a point made visible due to the hurricane. People that "deserted" their animals are not qualified to be pet-keepers. This discourse has a noticeable moral tone, as the "deserters" are immediately categorized as undeserving owners. However, as I outlined above, the fact that certain material conditions and the limited capabilities of vulnerable groups may have led to this "desertion" remains unspoken. Rather, the writer resorts to allusions about the possible flaws of the owners: naivety, ignorance, and perhaps even dullness, considering that it took them so long to react and to begin searching for their cat. Once again, the circumstances in which stranded people lived during the storm, and possible communication difficulties they may have experienced, are not accounted for. It is also noteworthy to read the last remark, "on a side-note," that the cat had not been spayed, implying that the owners' negligence of their animal actually began a long time before Katrina disrupted the bond for good.

In many of the custody disputes this line of argument - that former New Orleans owners were bad pet-keepers who did not nurture their animals sufficiently - was

Humanimalia: a journal of human/animal interface studies

Volume 9, Number 2 (Spring 2018) 
picked up by the adopters. New guardians, together with the animal organization movements that often acted as co-defendants, were striving to differentiate between the new and better keepers and their old, worse counterparts. A major issue in this regard are comments about the health and condition of the pets adopted. One case that attracted large public attention was that of Steve and Doreen Couture of St. Bernard Parish, Louisiana, whose dog, Master Tank, was fostered by Pam Bondi, an assistant state prosecutor in Florida (and today Attorney General of Florida). Bondi states that the St. Bernard dog she adopted from the Humane Society of Pinellas, Florida, was emaciated and suffered from heartworm when he came into her hands: "I love Noah [the new name she gave him], ${ }^{4}$ and just want to ensure he's well cared for, safe, and loved for the rest of his life" (Meadows); "I took a dog who was a walking skeleton. That's what was wrong with him before the hurricane" (Lee). According to Rhonda Rineker, a realtor from Dunedin, Florida, who adopted the Coutures' second dog, Nila, and renamed her Gracie, the animal had a "pre-hurricane condition of heartworm, a potentially fatal and easily prevented parasite" (Meadows). Attorney Joseph Bednarik, who commented fervidly on the custody disputes, stated regarding the stranded Katrina dog he himself adopted: "She was found under a house with a cut off rope around her neck. No identification, no rabies tag, and no registration were noted. Upon examination she was heartworm positive, tapeworm positive, and had advanced venereal cancer. The cancer was easily visible to anyone who cared to view her from behind. She was not spayed, [...] her prior owners cared for her miserably" (McNabb 79). Bednarik claims that as many as $98 \%$ of Katrina pets were not spayed or neutered, and about $85 \%$ had heartworms (ibid. 81). Similarly, Melisa Dudley, the president of a New Hampshire dog welfare organization that took some Katrina dogs into its care asserted: "I'd be hard-pressed to return the dogs, just given the condition they were in. Eight out of 10 were heartworm-positive. That didn't just happen because Katrina happened. [...] Others had old scars crossing their bodies. [...] Most weren't spayed or neutered" (Liebowitz). ${ }^{5}$

Leaving aside whether these statements are objectively correct, one can recognize here a reproach of Katrina pets' ex-owners - mostly poor people - as unreliable pet guardians. Significantly, an animal welfare discourse is being entwined here with judgments about people's character, and about more and less proper homes for pets. Such rhetoric also informed the narratives employed by the animal welfare groups, some of them written clearly in response to accusations regarding their adoption policies. Characteristically of these narratives, Animal Compassion Network, a North Carolinian association sued for giving away a St. Bernard Parish resident's Chihuahua, claims repeatedly that it saw its mission as adopting out Katrina pets "to suitable 
homes," "appropriate foster homes," or "responsible adoptive homes" (Jonsson; Animal Compassion Network).

This turns our attention back to the afore-mentioned perception of pet-keeping as privilege. The statements made by new adopters and animal welfare activists hint at the idea that if people cannot, or are not willing to, take care that their animals enjoy the greatest well-being, they should not keep them in their homes as pets. If people do not take their animals to the veterinarian to check for heartworms, if they do not pay for their cancer treatment, if they do not feed them the best and healthiest food, then they fail to be true pet guardians. This is the implication behind the perception of petkeeping as privilege and of pet-keepers as people who "spare no expense to ensure that their animals are as happy, contented and secure as they possibly can be" (Serpell, In the Company of Animals 15). In the case of the custody disputes of Katrina, this exclusion of the people whose care for their animals was allegedly deficient had very tangible consequences. As Pia Salk, a clinical psychologist and animal advocate from Santa Monica, California, who adopted a pit bull of a New Orleans locksmith from the Seventh Ward, put it, "I would not return the dog to a home I don't think she's safe in." She maintained the former owner didn't know how to treat against heartworm (Hall). Pam Bondi, the Florida assistant state prosecutor who adopted a stranded dog from St. Bernard Parish, justified her decision not to return the dog using the same line of argument: "If I thought I was sending him to a stable environment, where he would be cared for, as hard as it would be, I'd put him in my car and drive him back myself" (Lee). According to this logic, the Coutures, the Louisiana family who had owned the dog and supposedly failed to take care of his heartworm situation, proved unworthy of having a pet. Their bond with Master Tank, their lost dog, had to be dismantled for good, after Katrina had caused the first separation.

It is important at this point to note that adopters' allegations of bad care of pets were based not only on the deteriorated condition of their health, but also on animal-related practices considered typical of New Orleans lifestyles. Here the definition of bad petkeeping that fails to guarantee the well-being of an animal becomes enmeshed with stereotypical perceptions of cultural deficiency of poor African Americans in New Orleans. The most obvious point of reference in this regard was dog fighting. As Bednarik maintained, "dog fighting is extremely popular in New Orleans, so many of the animals rescued were severely marred pit bulls" (McNabb 81). One of Scott's covolunteers was pondering, with regard to a rescued Staffordshire Terrier (a pit bull type): "Red, this sweet creature with dogfighting in his breed's lineage and his closely cropped ears $[\ldots]$ was clearly a caricature of his past owner's Southern macho ideas of

Humanimalia: a journal of human/animal interface studies

Volume 9, Number 2 (Spring 2018) 
power" (Scott 124). In one extreme instance, a Connecticut shelter refused to give back the cats of a displaced Katrina family, claiming they were practicing witchcraft (McNabb 94).

This analogy is a revealing public denunciation of deviances generally ascribed to New Orleans townsfolk before, during, and after Katrina. As Alice Gavin suggests, a hegemonic reference to those lifestyles operates as a means of deploring certain milieux and the people to whom these pathological characteristics are attributed. The stigmatization of public housing in New Orleans as a hotbed of criminality and laziness is one example (Gavin). This instance resembles the above-mentioned stigma of dog fighting, also an infamous leisure activity generally attributed to a group of persons in an attempt to disapprove of them. In the same way that some people should not be entitled to reside in central "new New Orleans" following recovery, thereby rendering them effectively displaced from the community of townsfolk (Pardee 64, 77), others (or perhaps the same people) should be deprived of their place in the community of petkeepers. ${ }^{6}$ Their alleged practices with animals, which so drastically deviate from the hegemonic definition of proper pet-keeping, render them unfit to have pets.

"What's Best for the Dog:" The Disaster as Chance. Susanna Hoffman, writing about symbolic perceptions of order and disorder as manifested during the Oakland-Berkeley firestorm of 1991, claims that one momentous measure that residents resorted to almost obsessively in the aftermath of the catastrophe was getting pets back home, with the goal of restoring a sense of stability. The recovered pet-keeping emblematized a recovered order that had been lost, a renewed normality that had been brutally dismantled by the disaster. The ideal was a reestablishment of a reality in traditional and familiar forms (Hoffman 124). The disputes we are dealing with here show that a restoration of pet-keeping as it used to be is not necessarily what everyone was aiming for following Katrina. Animal welfare groups, as well as new foster families, had a different goal in mind. Focusing on the ways in which they attempted to justify why many sheltered animals left for new homes reveals a view concerning a potential correction of the arrangement of pet-keeping that the disaster rendered possible. Claiming to be placing the well-being of the animal before its status as property, the differentiation between "better" and "worse" pet-keepers was also a means of taking pets out of the "wrong" hands and delivering them to the "right" ones. The goal was not recovery of pre-disaster attachments between people and pets, but the creation of new ones - a correction that was pursued in accord with the hegemonic perception of good pet-keeping. 
To fully understand the custody disputes under discussion, it is important to consider the legal situation regarding the keeping, and especially owning, of pets in the United States. Since the 19th century, the law in most states has viewed pets, especially dogs, largely as private property - like livestock. Legally, pets are like commodities that have certain value for their owners, and not subjects that have their own interests and desires, let alone rights (Hunter and Brisbin, Jr. 55-60; Dayan 213-227, 245-248; Baum 107-108, 118; Hankin 321). With few exceptions, this view of animals and pets as mere objects of human interests still has a hold on the legal system (Kelch 238; Hankin 324, 337). The status of pets as property has enormous significance for the question of owner-pet affiliations and the possibility of dismantling them for the sake of creating new ones that will be of more benefit to the animals. As animal rights scholars assert, if pets and other animals are considered property, their own best interest has only marginal importance when weighed against the possession interests of their owners (Francione; Kelch 235). Insufficient care that is detrimental to the well-being of the pet does not justify extinguishing property rights and eliminating the relationship between an owner and his or her animal property. In this legal framework, the welfare and quality of life of the animals and the kind of treatment they receive from their owners are not an essential factor of pet-keeping. Pet-keeping, like any other form of animal husbandry, is little more than the physical possession of the animals by their lawful owners. It has little to do with a privileged status or existence of the animals in question (cf. Hunter and Brisbin, Jr. 67-68).

Under such conditions, it is easy to see why most of the plaintiffs in the Katrina custody disputes eventually received their animals back, either by court decision or after a settlement had been reached (McNabb; Shuffield 122; Anderson 378-379). Even though plaintiffs had less financial means than defendants, the traditional view of animals as property guaranteed their victory in court. To win the case, they did not have to prove that they took good care of the animals, but simply that the animals belonged to them (Huss 1146). Cases inevitably focused on the damage that was done to them by dispossessing them of their animal property, and not on the damage they might have inflicted on the animals by not treating them against heartworms. Ironically, the same disregard of animals' interests that, during the storm, led to the removal of pets from evacuation transports and to their separation from their poor owners now paved the way for their reunion with them.

Initially, the animal welfare organizations that were sued saw the disputes as a rare opportunity for setting a legal precedent for referring to animals as living creatures whose well-being must be accounted for, and not merely as soulless pieces of property

Humanimalia: a journal of human/animal interface studies

Volume 9, Number 2 (Spring 2018) 
possessed by humans. The disputes generated considerable interest among animal rights activists and organizations. An article on the Bondi dispute stated, for example, that "[c]ases like hers are being closely watched by animal rights activists and animal law experts, who say judges could carve new precedent if they consider a pet's best interests when deciding who gets to keep it" (Jenkins, "Law a Little Fuzzy"). ${ }^{7}$ In the past decades animal welfare associations' policy and ideology regarding companion animals has changed in one major aspect: instead of focusing their attention on acts of wanton cruelty against companion animals - the usual approach of humane societies in the past - they now see their mission in positively promoting good pet-keeping as conducted by caring, responsible guardians. This new policy goes along with condemning "bad" keepers not for cruelty per se, but for negligence and insufficient care, or so-called "passive cruelty" (Hunter and Brisbin, Jr. 60-65, 68). In the context of Katrina's custody disputes, changing the legal status of pets from property to independent living beings who deserve good care was an instrument of achieving such a positive improvement in pet-keeping and in pets' lives: it would have made possible and legitimate the movement of pets from mere owners who treated them poorly to true guardians who were versed in the principles of good pet-keeping and promised to make sure they lived as happily as possible. ${ }^{8}$ Philip G. Kircher, the lawyer of a psychotherapist and doctor from Doylestown, Pennsylvania, who adopted the mutt of a New Orleans evacuee, summarized the non-anthropocentric principle that would have mandated such a movement: "We're trying to do what's best for the dog" (Boccella).

Under these circumstances, it is understandable that for animal welfare organizations and the adopters who were their allies and shared their values the new reality Katrina created was, to a large extent, a desirable one. It changed the lives and status of animals for the better. Returning to the case of the Couture family and Pam Bondi, an article in a local newspaper paraphrased Bondi's argument, that the adopted dog "needs medical care that she doesn't think the previous owners [...] can provide. [...] 'Morally, ethically, legally, it's not even a close call to me. I'm saving his life and protecting him.' " Although she "won't discuss how much she has spent on Noah," she reported he "gets fresh chicken and beef with every meal" (Jenkins, "Dispute Nips at Prosecutor's Heels"). In contrast to this luxurious life, her local veterinarian in Florida apparently told her the dog "would not survive living outdoors back in Louisiana" (Carlton). In other words, with Bondi, the dog's life was elevated. He now lived like a genuine pet with all the benefits received from a responsible guardian. In another dispute, that of New Orleans evacuee Paula Duming's lawsuit against Wendy Shieh and Dustin Jones, San Diego residents who adopted her stranded dog Pablo, "[t]he couple refused [to hand him back] on the grounds that they are able to provide Pablo with better care than Ms. Duming who is on a fixed income" (Burroughs). Dale Green, the director of the 
New Hampshire Rottweiler rescue organization For the Love of Dog, which adopted some Katrina dogs, stated things plainly: "the sad fact of the matter is that the majority of the dogs that came out are better off up here" (Liebowitz). All of these statements illustrate a picture in which the assumed movement of pets from poor Louisiana and Mississippi owners to richer ones in affluent towns in Florida, California, or New England is a welcome process. As a subtext, it implies that only financially established people should be admitted to the community of pet-keepers. It excludes the poor from pet-keeping (cf. Smith, Governing Animals 86). Implicit in placing the welfare of the animals - "what's best for the dog" - as first priority is that it would be undesirable for dogs and cats to be part of low-income households.

Considering these assertions, we can recognize the great positive impact that Katrina had in the eyes of new guardians and, especially, animal welfare organizations. Bearing in mind the above-mentioned traditional, rigorous attribution of an individual pet to one specific owner or family, we are in a position to assess the huge opportunity the catastrophe opened up for those discontented with the current state of pet-keeping in the United States and wishing to reform it. As a natural disaster of gigantic dimensions, Katrina, in the eyes of animal welfare activists, made it possible to take pets away from their unqualified, poor owners. The stranding of so many animals and the disconnection from their homes facilitated something that is impossible to achieve under normal conditions, namely the reshuffling of pets and keepers. As Scott admits, "[f]or some pets, Katrina, while devastating in so many ways, was the best thing that ever happened to them" (198). She tells a story about a "yard dog" whose former owner had "never taken the time to name" him. He was "aggressive," "feral-like," and "scared," as well as unhealthy. In contrast to his former life, this dog received much love and ample room to move about at the Tylertown shelter. In this view, Katrina's stranded pets were rescued in a double sense: first, from the flood; second, from the households of people who treated them badly (cf. Weaver 699). In the process, they turned from "yard dogs" into real "pets."

A closer look at the activities of animal welfare organizations in the immediate aftermath of the storm substantiates the idea that for many of them Katrina opened a chance of transferring animals from bad owners and bad environments to more appropriate households for pet-keeping. A main issue is the rapidity with which organizations adopted out pets to new foster homes. In a large number of court cases, plaintiffs raised the accusation that the animal shelters that had been holding their pets were sending them to new homes after very short periods, without conducting an exhaustive search for legal owners and contrary to state laws about the minimum

Humanimalia: a journal of human/animal interface studies

Volume 9, Number 2 (Spring 2018) 
amount of time shelters are obliged to harbor a displaced animal before delivering it to a new foster home (Meadows). One rescue volunteer claims to have "encountered hundreds of cases of shelters that put up pets for adoption without first attempting to find owners" (Roddy). While it is true that the temporary shelters had limited housing capabilities, compared to the enormous number of pets stranded as a result of the hurricane, it seems that such objective reasons are not the only ones explaining the hasty adopting out of many of the animals. The North Carolina Animal Compassion Network (ACN), which was sued for adopting out a dog belonging to a Louisiana person, published its own version of its actions immediately following Katrina:

Soon after [the hurricane slammed the Gulf Coast] the ASPCA asked if ACN would accept any cats and dogs from the flooded Louisiana animal shelters into our foster homes. Because these were surrendered shelter animals they had no place to go and no one looking for them; we willingly opened our hearts and foster-network to them. [...] With the arrival of each transport from the disaster area, our medical staff and volunteers immediately recorded the intakes, began medical assessments and treatments, and matched animals with appropriate foster homes. (Animal Compassion Network)

From this portrayal of the events we can learn a few things: in ACN's perception, the animals that came to its facilities were clearly and exclusively surrendered ones ("these were surrendered shelter animals"), meaning that they no longer belonged to anyone, and that they had the status of feral pets, due to an act of abandonment by Katrina evacuees. In other words, the animals were actively "surrendered" and not, for instance, lost or gone astray without owners being able to determine their destiny. Based on this assumption, the animals had been in fact rendered available for adoption straight away. Despite the claim, that "we also initiated reunification efforts using any clues we could find" (ibid.), it seems that from the beginning, new owners (from "appropriate foster homes"), and not the old ones, were desired. Keeping in mind the concerted efforts that Best Friends, for instance, made to locate previous owners, the brevity of ACN's account of its own attempts at reuniting, and their focus on fostering, are quite astonishing. The actual outcome is not surprising: according to the account only $10.4 \%$ of the animals were reunited (ibid.). Compared with McNabb's assessment of $20 \%$ of the total animals rescued returning to former owners, this is a quite meager number (McNabb 76).

To some degree, this interpretation supports the assumption that "rescue organizations' mentality that those who left their pets behind during Hurricane Katrina do not deserve 
them" (ibid. 76; cf. Dickey 234) dictated many of their practices. A representative of Voices for Animals, a Pennsylvania shelter that was believed to adopt out the poodle of a retired sheet-metal worker from the Ninth Ward to a woman in Pittsburgh, admitted that "groups are struggling over what to do with animals they suspect 'suffered serious long-term neglect' before Katrina" (Boccella). The potential disinclination toward reunifications that characterized such groups is further corroborated by Kathrine Glover and Rob Robison, who following Hurricane Andrew (1992) developed a system to help reunite owners and their pets. During Katrina, Glover and Robison attested that they "liked their [Best Friends'] emphasis on reuniting animals with their owners, which is not always the case with other animals groups" (Perkins).

Indeed, many shelters were not really attuned to owners attempting to find out the whereabouts of their pets and, on the contrary, laid many obstacles in their path. A case in point is the above-mentioned story of the Petfinder post, in which a cat, after being located, suddenly " 'disappeared' at Southern Animal Foundation, with no record of her." According to the responder, "I really stopped looking for her about a month ago, when I saw that all roads came to a dead-in on this cat. Someone knows where she is, but they will never talk." As for the Pinellas Humane Society, where Pam Bondi acquired the dog of the Couture family, people who believed their pets reached the society's shelter and the volunteers aiding them have testified that open communication with officials was extremely difficult to attain. First, officials claimed that the shelter was not holding the sought pets (even contrary to evidence), and later they resorted simply to not returning calls and e-mails (Lee). Paula Duming, whose dog was adopted out to a San Diego couple, contacted the Animal Benefit Club of Phoenix, Arizona, the organization that gave him away, only to be consistently fended off by the director, Dee Kotinas. First, Kotinas claimed the dog adopted was not the one Duming was claiming; then, after Duming brought her a photo, she tried to put her off with misstatements about the appearance and character of the dog she delivered to foster, and eventually she simply screamed at her, "It's over. It's adopted and it's legal. Move on. Get over it." Kotinas even testified in court that she did not bother to look through the ad of the found dog in Petfinder (Battista; Clancy and Bazar).

Hence, we can conclude that on the side of organizations, reunions following Katrina or the lack thereof were to a large extent a matter of choice. When the choice was made, it was often dictated by non-anthropocentric motivations regarding the well-being of the pet, combined with more or less implicit class-based views about the kind of household an animal would have a better life in. Those views were grounded largely on considerations of the material capabilities and behavioral habits of guardians, and

Humanimalia: a journal of human/animal interface studies

Volume 9, Number 2 (Spring 2018) 
therefore were tightly intertwined with discourses about poverty and the mentalities of poor, Southern people. Be that as it may, for certain animal lovers, Katrina was a rare chance to effectively upgrade the social status of a considerable number of pets. ${ }^{8}$ For them, recovery meant building new human-animal companionships, but at the same time demolishing old ones. ${ }^{9}$

Conclusion. In view of the magnitude, both of the number of lives lost and of the cost of the damage caused, Hurricane Katrina was a radical event. Yet, Katrina could only become so extraordinarily destructive because of the ordinary social structures typical for the region it assailed. In this sense, Katrina was not really about the falling apart of world orders. Socially, its impact had a firm logic that demonstrated the "normal," rather than the exceptional. As an "unnatural disaster" it was not a monstrous happening, stemming from spheres beyond the human, but one that was tightly tied to established patterns that characterized the way a certain human society was structured. By relating the major social aspects that informed the disaster during the recovery phase to the issue of post-Katrina pet-keeping, we can gain an insight into the extent to which this seemingly innocent hobby-like occupation is also played out in the framework of familiar social dynamics that determine interactions among individuals and groups. Elizabeth Finch, the dog-keeper from Central Park quoted at the beginning of this article, was absolutely right when she maintained that Katrina's stranded pets fit "into a bigger model of discrimination." It is impossible to tell the story of these animals without placing them side by side with the more general, disturbing social elements that constituted this "unnatural disaster." But equally, the embedded nature of the sociology of Katrina and that of pet-keeping demonstrates that pet-keeping itself extends beyond the mere personal bond between a keeper and a companion into the domain of the political and the socially controversial. It means that not only did the hurricane itself have a considerable social dimension; it also enabled the quite common social reality of pet-keeping, an element that is usually blurred and unaccounted for, to rise to the surface. Katrina, in other words, taught us something very fundamental about the social character of our intimate companionship with certain animals that we cherish the most.

However, the custody conflicts studied in this article tell the story not only of a familiar social reality, but also of its disruption (cf. Weaver 705-706). As we have seen, the perception of the movement of pets from their former owners to adopters outside of Louisiana and Mississippi as a positive development was rooted in a perception of petkeeping as privilege. New guardians and animal welfare movements called into question the status of former owners as pet-keepers. Their allegations of poor treatment reveal how the hegemonic understanding of pet-keeping as privilege works to exclude 
certain people from owning pets. On the other hand, the struggle by former owners to reclaim their pets may be seen as an act of resistance against their exclusion, and, by implication, against the perception of pet-keeping as privilege. By fighting to reestablish their bonds with their dogs and cats even after their lives were shattered by the hurricane, former owners hinted at the possibility that love for pets does not necessarily have to go along with ensuring their greatest well-being. They suggested that it is possible for keepers to be emotionally attached to their animals even if they didn't treat them against heartworms or fleas (according to one estimate, more than a quarter of pet owners in the U.S. "fail" to give their animals "basic veterinary care" [Pierce 4]). They insinuated that sometimes even "yard dogs" might be "pets," and hence called into question the ideology that ties pets to domesticity and the comfort of the home. These ideas go far beyond Katrina and the custody disputes it created. They challenge us to rethink our common perceptions of what "pets" are, and they call upon us to embrace a much more open, dynamic definition of this category (cf. Eddy; Serpell, "Pet-Keeping"). Their disruptive force originated in the reality of social conflicts, but it is felt most severely on the level of theory.

Interestingly, the disruption of common perceptions of "pets" as privileged animals was already taking place during the catastrophe itself: without forgetting the great suffering that all animals were exposed to, it is challenging to refer to Scott's testimony, that not only "ordinary" pets, but many other animals, "regardless of their species" and "the kind of animals they were," enjoyed the complete mindfulness of the rescuing volunteers attending to their efforts in the streets of New Orleans (114, 144, 153). ${ }^{10}$ As a truly exceptional, tragic event, Katrina at least hinted at the direction of a more equal animal community, that in this regard really differed from the human one.

\section{Notes}

1. In areas severely damaged, a total of $45.8 \%$ of the population was black, in areas undamaged this was only as high as $26.4 \%$ (Hartman and Squires 275 ).

2. However, this type of close attachment of keepers to their pets as demonstrated in the course of a natural disaster is only partly a new phenomenon. Similar behavior is documented, for instance, in the 1927 Mississippi flood (Lübken 254-255).

3. According to Steven Wise, an animal rights lawyer who represented ex-owners, "[t]hese animals are only moving in one direction, from poor to rich and from black to white and, as an American, that really bothers me" (Jonsson).

Humanimalia: a journal of human/animal interface studies

Volume 9, Number 2 (Spring 2018) 
4. The significance of the renaming of the adopted dog came recently once again to public attention, as "Late Show" host Stephen Colbert mentioned the Bondi-Couture dispute in relation to Bondi's connections with, and support for, Presidential candidate Donald Trump. On the September, 8, 2016 edition of the show, Colbert half-joked that "refusing to give back a dog to flood victims, but naming the dog after the most famous flood victim of all time is just cold" (Burris).

5. According to Leslie Irvine, a sociologist of human-animal relations who volunteered during Katrina in a pet shelter in Gonzalez, Louisiana, only a few of the animals brought to the facility from New Orleans were neutered. This can be read as another indication of the low socio-economic background of the owners of pets left behind. Irvine supplies one more interesting fact in this regard, namely, that most of the dogs were mixed breeds, while many others were pit bulls (30; cf. Dickey 232).

6. Donna Thomas of Animal Rescue New Orleans (ARNO) has pointed out that snobbery had been a factor in animal welfare organizations' efforts at recovery: "There's this assumption that somehow everybody in New Orleans was poor and uneducated and incapable of loving their pets" (Meadows).

7. When, four years later, Bondi ran for the office of Florida Attorney General as the Republican candidate, her Democrat opponents resurrected the memory of the dog dispute, even releasing a YouTube video featuring the Coutures, with the aim of convincing the public of Bondi's deficient sense of social justice. Asked whether she was afraid this could effectively harm her chances in the campaign, she responded confidently: "Not at all. [...] I've received a tremendous amount of support from people and animal rights activists, and no criticism at all" (Nipps).

8. The differentiation between "guardians" that are true "caregivers" of their pets and "owners" who "treat their animals like objects" is a central aspect of present-day pet ethics terminology; see Pierce 213-215.

9. For recovery as demolition (of houses) see Gotham and Greenberg 109. Pet-keeping following Katrina is by no means the first example in American history of an elite group perceiving the aftermath situation of a hurricane as a chance to assert its authority and reshape society, in line with its own views of the desired conditions for the future. The hurricanes that attacked the colonies of the North-American eastern coast during the 17th and 18th centuries had already made it possible for richer settlers to get hold of the property of weaker ones, who as a consequence of the calamity were forced into 
bankruptcy (Mulcahy 28-29). At a much later date, the extremely deadly storm that slammed Galveston, Texas, has enabled a new business elite of Progressive-minded people to gain dominance in the local political arena and determine circumstances in the town according to their ideals of reform and professionalism (Bixel).

10. Scott tells, for example, of the rescuing of geese, ducks, chickens, pigs, spiders, snakes, turtles, and many more species (not to mention the stray populations of cats and dogs) that received top-quality care by their human rescuers. See also Moore. As a matter of fact, in earlier natural disasters from the first half of the twentieth century farm animals received greater consideration, and maybe even more devoted care, from rescuing authorities than pets, thanks to their material and economic worth (Lübken 255-256).

\section{Works Cited}

Anderson, Zandra. "Legal Issues Involving Animal Associations and Individuals Helping Animals." Litigating Animal Law Disputes: A Complete Guide for Lawyers. Joan Schaffner and Julie Fershtman, eds. American Bar Association, 2009. 355-436.

Animal Compassion Network. “ACN Disaster Response.” Accessed January 25, 2012.

Bankoff, Greg. "Time is of the Essence: Disasters, Vulnerability, and History." International Journal of Mass Emergencies and Disasters 22.3 (November 2004): 23-42.

. "Learning about Disasters from Animals." Learning and Calamities: Practices,

Interpretations, Patterns. Heike Enger, Marén Schorch, and Martin Voss, eds. Routledge, 2015. 42-55.

Battista, Francis. "Pablo's Trial: A Spectator's View." Best Friends Network. Accessed January 27, 2012.

Baum, Marsha L. "'Room on the Ark?' The Symbolic Nature of U.S. Pet Evacuation Statutes for Nonhuman Animals." Considering Animals: Contemporary Studies in HumanAnimal Relations. Carol Freeman, Elizabeth Leane, and Yvette Watt, eds. Ashgate, 2011. 105-118.

Bevc, Christine A., Keith Nicholls, and J. Steven Picou, "Community Recovery from Hurricane Katrina: Storm Experiences, Property Damage, and the Human Condition."

Humanimalia: a journal of human/animal interface studies

Volume 9, Number 2 (Spring 2018) 
The Sociology of Katrina: Perspectives on a Modern Catastrophe. David L. Brunsma, David Overfelt, and J. Steven Picou, eds. Rowman and Littlefield, 2010. 135-156.

Bixel, Patricia Bellis. "It Must Be Made Safe:' Galveston, Texas, and the 1900 Storm." American Disasters. Steven Biel, ed. New York UP, 2001. 223-246.

Blake, Eric S., Christopher W. Landsea, and Ethan J. Gibney. "The Deadliest, Costliest, and most Intense United States Tropical Cyclones from 1851 to 2010 (And Other Frequently Requested Hurricane Facts)." NOAA Technical Memorandum NWS NHC-6, 2011. Accessed March 7, 2016.

Boccella, Kathy. “Tug-of-War Erupts over Katrina Pets.” Philadelphia Inquirer. July, 16, 2006.

Brinkley, Douglas. The Great Deluge: Hurricane Katrina, New Orleans, and the Mississippi Gulf Coast. Morrow, 2006.

Burris, Sarah K. "Stephen Colbert: 'Pam Bondi is the Only Person in the World Who Made Money from Trump University."' Raw Story. September, 9, 2016, Accessed July 28, 2017. Web.

Burroughs, Anna. "Hurricane Katrina Dog at Center of Legal Battle." Yahoo! Voices. March, 12, 2007. Accessed January 26, 2012. Web.

Carlton, Sue. "There are no Losers in Katrina Dog Case." St. Petersburg Times. May, 25, 2007.

Clancy, Michael and Emily Bazar. "Katrina Creates Custody Dogfight." USA Today. March, 13, 2007.

Crowley, Sheila. "Where is Home? Housing for Low-Income People after the 2005 Hurricanes." There is no Such Thing as a Natural Disaster: Race, Class, and Hurricane Katrina. Hartmann, Chester and Gregory D. Squires, eds. Routledge, 2006. 121-166

Cutter, Susan L., Christopher T. Emrich, Jerry T. Mitchell, Bryan J. Boruff, Melanie Gull, Matthew C. Schmidtlein, Christopher G. Burton, and Ginni Melton. "The Long Road Home: Race, Class, and Recovery from Hurricane Katrina." Environment 48.2 (2006): 820. 
Dayan, Joan. The Law Is a White Dog: How Legal Rituals Make and Unmake Persons. Princeton UP, 2011.

Dickey, Bronwen. Pit Bull: The Battle over an American Icon. Alfred A. Knopf, 2016.

Dynes, Russel R. and Havidán Rodríguez. "Finding and Framing Katrina: The Social Construction of Disaster." The Sociology of Katrina: Perspectives on a Modern Catastrophe. David L. Brunsma, David Overfelt, and J. Steven Picou, eds. Rowman and Littlefield, 2010. 25-36.

Eddy, Timothy J. “What is a Pet?” Anthrozoös 16.2 (2003): 98-105.

Francione, Gary L. "Animals-Property or Persons?" Animal Rights: Current Debates and New Directions. Sunstein, Cass R and Martha C. Nussbaum, eds. Oxford UP, 2004. 108142.

Fudge, Erica. Pets. Acumen, 2008.

Gavin, Alice. "Reading Katrina: Race, Space, and an Unnatural Disaster." New Political Science 30.3 (August 2008): 325-346.

Glick, Megan H. "Animal Instincts: Race, Criminality, and the Reversal of the 'Human'." American Quarterly 65.3 (September 2013): 639-59.

Gotham, Kevin Fox and Miriam Greenberg. Crisis Cities: Disaster and Redevelopment in New York and New Orleans. Oxford UP, 2014.

Graham, Darwin Bond. "The New Orleans that Race Built. Racism, Disaster, and Urban Spatial Relationships." Seeking Higher Ground: The Hurricane Katrina Crisis, Race, and Public Policy Reader. Manning Marable and Kirsten Clarke, eds. Palgrave McMillan, 2008. 17-32.

Grier, Kathrine. Pets in America: A History. U of North Carolina P, 2006.

Grimm, David. Citizen Canine: Our Evolving Relationship With Cats and Dogs. PublicAffairs, 2014.

Hall, Clara, “There's a Dog in This Hunt.” Los Angeles Times. August, 27, 2007. 
Haney, Timothy J., James R. Elliott, and Elisabeth Fussel. "Families and Hurricane Response: A Framework for Understanding Family Evacuation Strategies, Stress, and Return Migration." The Sociology of Katrina: Perspectives on a Modern Catastrophe. David L. Brunsma, ,David Overfelt, and J. Steven Picou, eds. Rowman and Littlefield, 2010. 77102.

Hankin, Susan J. "Not a Living Room Sofa: Changing the Legal Status of Companion Animals." Rutgers Journal of Law E Public Policy 4.1 (Winter 2007): 314-410.

Haraway, Donna J. When Species Meet. U of Minnesota P, 2008.

Hartman, Chester and Gregory D. Squires. "The Social Construction of Disaster: New Orleans as the Paradigmatic American City." Seeking Higher Ground: The Hurricane Katrina Crisis, Race, and Public Policy Reader. Manning Marable and Kirsten Clarke, eds. Palgrave McMillan, 2008. 271-294.

Hoffman, Susana M. "The Monster and the Mother: The Symbolism of Disaster." Catastrophe and Culture: The Anthropology of Disaster. Idem and Anthony Oliver-Smith, eds. School of American Research Press, 2002. 113-141.

Hunt, Melissa, Hindi Al-Awadi, and Megan Johnson. "Psychological Sequelae of Pet Loss Following Hurricane Katrina." Anthrozoös 21.2 (2008): 109-121.

Hunter, Susan, and Richard A. Brisbin, Jr. Pet Politics: The Political and Legal Lives of Cats, Dogs, and Horses in Canada and the United States. Purdue UP, 2016.

Huss, Rebecca J. "The Pervasive Nature of Animal Law: How the Law Impacts the Lives of People and Their Animal Companions." Valparaiso University Law Review 43.3 (Spring 2009): 1131-1154.

Irvine, Leslie. Filling the Ark: Animal Welfare in Disasters. Temple UP, 2009.

Ishiwata, Eric. “'We are Seeing People We didn't Know Exist:' Katrina and the Neoliberal Erasure of Race." The Neoliberal Deluge: Hurricane Katrina, Late Capitalism, and the Remaking of New Orleans. Cedric Johnson, ed. U of Minnesota P, 2011. 32-59.

Jenkins, Colleen. “Dispute Nips at Prosecutor's Heels." St. Petersburg Times. July 04, 2006. 
__. "Law a Little Fuzzy." St. Petersburg Times. July 16, 2006.

Jonsson, Patrick. "Lost in Katrina and in New Homes: Whose Pet Now?" Christian Science Monitor. July 21, 2006.

Katz, Cindi. "Bad Elements: Katrina and the Scoured Landscape of Social Reproduction." Gender, Place, and Culture 15.1 (February 2008): 15-29.

Kean, Hilda. "The Moment of Greyfriars Bobby: The Changing Cultural Position of Animals 1800-1920." A Cultural History of Animals in the Age of Empire, 1800-1920. Kathleen Kete, ed. Berg, 2007. 25-46.

Kelch, Thomas G. "Toward a Non-Property Status for Animals." The Feminist Care Tradition in Animal Ethics. Josephine Donovan and Carol J. Adams, eds. Columbia UP, 2007. 229-249.

Kim, Claire Jean. Dangerous Crossings: Race, Species, and Nature in a Multicultural Age. Cambridge UP, 2015.

Lee, Demorris A. “Who are Pets' Real Owners after Katrina Left Them Homeless?" St. Petersburg Times. May 16, 2006.

Leland, John. “Dogs are People too." New York Times. September 11, 2005.

Liebowitz, Sarah. "Who Rightfully Owns Ah Boo?" Concord Monitor. September 08, 2006.

Londoño, Ernesto. "Fangs are Bared over Md. Group's Katrina Dog Rescues." Washington Post. August 14, 2006.

Lübken, Uwe. "'Poor Dumb Brutes' or 'Friends in Need'? Animals and River Floods in Modern Germany and the United States." Beastly Natures: Animals, Humans, and the Study of History. Dorothee Brantz, ed. U of Virginia P, 2010. 245-263.

McNabb, Megan. "Pets in the Eye of the Storm: Hurricane Katrina Floods the Courts With Pet Custody Disputes." Animal Law Review 14.1 (Fall 2007): 72-108.

Humanimalia: a journal of human/animal interface studies

Volume 9, Number 2 (Spring 2018) 
Meadows, Bob. “Whose Dog is it Anyway?” People. August 21, 2006.

Moore, Solomon. "Animal Refuge Strives to Corral Pets-and Despair." Los Angeles Times. September 11, 2005.

Mulcahy, Matthew. "'A Tempestuous Spirit Called Hurri Canno:' Hurricanes and Colonial Society in the British Great Caribbean." American Disasters. Steven Biel, ed. New York UP, 2001. 11-38.

Nast, Heidi J. “Critical Pet Studies?" Antipode 38.5 (November 2006): 894-906.

Nipps, Emily. "As Bondi Runs for Attorney General, Bitterness over Dog Lingers." Tampa Bay Times. September 4, 2010.

Pardee, Jessica W. "Living through Displacement: Housing Insecurity among LowIncome Evacuees." Displaced: Life in the Katrina Diaspora. Lynn Weber and Lori Peek, eds. U of Texas P, 2012. 63-78.

Perkins, Nancy. "Saving Animals: Volunteers Learn Search-Rescue Methods in Case of Emergency." Desert News. June 18, 2007.

Pierce, Jessica. Run, Spot, Run: The Ethics of Keeping Pets. U of Chicago P, 2016.

Reilly, Benjamin. Disaster and Human History: Case Studies in Nature, Society, and Catastrophe. McFarland, 2009.

Roddy, Dennis B. "Katrina Victim, 86, Sues to Have his Rescued Poodle Returned." Pittsburgh Post-Gazette. June 25, 2006.

Scott, Cathy. Pawprints of Katrina: Pets Saved and Lessons Learned. Wiley Publishing, 2008.

Serpell, James. "Pet-Keeping in Non-Western Societies. Some Popular Misconceptions." Anthrozoös 1.3 (1987): 166-174.

. In the Company of Animals: A Study of Human-Animal Relationships. Cambridge UP, 1996. 
Shuffield, Lacy L. "Pet Parents-Fighting Tooth and Paw for Custody: Whether Louisiana Courts Should Recognize Companion Animals as More than Property." Southern University Law Review 37.1 (2009): 101-125.

Smith, James Patterson. Hurricane Katrina: The Mississippi Story. UP of Mississippi, 2012.

Smith, Kimberly K. Governing Animals: Animal Welfare and the Liberal State. Oxford UP, 2012.

Steinberg, Phil. "What is a City? Katrina's Answers." What is a City? Rethinking the Urban after Hurricane Katrina. Idem and Rob Shields, eds. U of Georgia P, 2008. 3-29.

Steinbrecher, Aline. "Hunde und Menschen: Ein Grenzen auslotender Blick auf ihr Zusammenleben (1750-1850)." Historische Anthropologie 19.2 (2011): 192-210.

Thompson, Kirrilly, Danielle Every, Sophia Rainbird, Victoria Cornell, Bradley Smith, and Joshua Trigg. "No Pet or their Person Left Behind: Increasing the Disaster Resilience of Vulnerable Groups through Animal Attachment, Activities, and Networks." Animals 4.2 (June 2014): 214-240.

Tierney, Kathleen. The Social Roots of Risk: Producing Disasters, Promoting Resilience. Stanford Business Books, 2014.

Waterhouse, Carlton. "Failed Plans and Planned Failures: The Lower Ninth Ward, Hurricane Katrina, and the Continuing Story of Environmental Injustice." Hurricane Katrina: America's Unnatural Disaster. Jeremy I. Levitt and Matthew C. Whitaker, eds. U of Nebraska P, 2009. 156-182.

Weaver, Harlan. "'Becoming in Kind:' Race, Class, Gender, and Nation in Cultures of Dog Rescue and Dogfighting." American Quarterly 65.3 (September 2013): 689-709.

Zotarelli, Lisa K. "Broken Bond: An Exploration of Human Factors Associated with Companion Animal Loss during Hurricane Katrina." Sociological Forum 25.1 (March 2010): 110-122.

Humanimalia: a journal of human/animal interface studies

Volume 9, Number 2 (Spring 2018) 